\title{
Sustainable Program Management: Hierarchical Causal Systems
}

\author{
Bongs Lainjo ${ }^{1}$ \\ ${ }^{1}$ Cybermatic International, Montréal, Canada \\ Correspondence: Bongs Lainjo, Cybermatic International, 105-5700 Cavendish Blvd, Montréal, QC H4W 1S8, \\ Canada. Tel: 514-690-8022. E-mail: bsuiru@icloud.com \\ Received: November 29, 2020 \\ Accepted: December 20, 2020 \\ Online Published: January 30, 2021 \\ doi:10.5539/jsd.v14n1p84 \\ URL: https://doi.org/10.5539/jsd.v14n1p84
}

\begin{abstract}
This research paper focuses on strengthening program management protocols, which can help in mitigating nuances along with duplication, and redundancies. In this context, seven components have been considered for facilitating the achievement of sustainable management of a development program. Thus, for conducting this study, a conceptual framework of the "CARROT-BUS" model has been taken into due consideration. CARROT mainly stands for Capacity, Accountability, Resources, Results, Ownership, and Transparency, which emphasizes enabling the environment while BUS is perceived as a bottom-up strategy. Correspondingly, this holistic and causal model can be considered to be conceptually synonymous with Abraham Maslow's hierarchy of needs theory. Additionally, each step of the model needs to be well-defined and described. Hence, designing and implementing sustainable development programs can be considered to be complex. Therefore, the systems presented in this abstract are a way of addressing these complexities.

Herein, for conducting this study, secondary sources have been taken into high consideration. The use of these sources has significantly assisted in enhancing the existing knowledge on the identified issue in detail. Thus, the study has been able to understand the importance of sustainability in the present scenario, especially in project management. Based on the overall findings, it can be stated that sustainability is one of the key aspects, which are maintained by organizations all around the world for attaining success.
\end{abstract}

Keywords: pyramid, causality, systems, sustainable, hierarchical, program, and management

\section{Introduction}

Across all management landscapes along with development program management, the outcomes are not found to be satisfactory even after the implementation of compelling strategies. This often emerges from unexpected and uncontrolled circumstances resulting from internal, as well as external factors. In some cases, poor budget oversight and inhibiting environments contribute substantially to derailing programs. In this context, Murphy's Law states, "Anything that can go wrong, will go wrong" Program management is no exception (Singh, 2020).

\subsection{Problem Statement}

In the last four decades, both bi-lateral and multi-lateral funding agencies have largely invested to develop countries to improve the quality of life of the intended beneficiaries. An objective analysis of these initiatives has led to obtaining mixed conclusions (Biscaye, Reynolds, \& Anderson, 2017). On the other hand, some have achieved meaningful results, while others are continuing to depict insignificant achievements. One of the key challenges is associated with that of designing a 'sustainable' development management assistance model. This model can be replicated and can further serve as gold standards for developing sustainable programs. One significant challenge, which is to be addressed by both funding agencies and Implementing Partners (IPs), is that of defining success. Herein, a question arises whether success needs to be defined in terms of events, processes, or both (BCI, 2019).

Additionally, establishing a broad and binding agreement among stakeholders for a complex developmental undertaking often remains difficult, evasive, and convoluted. All the stakeholders need to work cordially to attain agreement among them. This is because it can have a direct impact on the outcome. Therefore, planning and preparatory dialogue(s) should not be confined only to the definition of desired outputs/outcomes. This is because planning and preparatory dialogue is perceived by the intended beneficiaries at the design phase. However, they must also be considered in the implementation and subsequent phase (Asian Development Bank, 2020). 


\section{Literature Review}

This literature review section focuses on highlighting the existing models, frameworks, or systems on program management, thereby emphasizing similarities, differences, and scope as compared to the CARROT-BUS model. As per evidence-based research, there are limited documents available on the program management framework. In this context, most of the available frameworks are on the issue of project management, especially that of the corporate world. Besides, there is no literature available on the CARROT-BUS model. Thus, the review of the result is based on the available literature on project/program management.

Briassoulis (2001) stated that increasing efforts on "sustainability" in project/program management is found to be promising. In this context, there are also some challenges because "sustainability" is difficult to define in concrete and operational terms. It is currently based on instinctive manifestations. Based on the study findings of Chawla, Chanda, Angra, and Chawla (2018, p. 157), it can be understood that "Sustainability in project operations such as financial, social and environmental sustainability is one of the most prominent issues of the present times to address". On the other hand, Silvius (2013) asserted that a structured review of the available literature on sustainability along with project management will answer two research questions: How is sustainability defined or considered in the context of program management? and How does considering sustainability impact program management?

In this concern, population changes, climate changes, and energy resource constraints are the three driving forces that are undergoing major transitions. It is further essential to move toward 'sustainability' while implementing the projects and programs. Real 'sustainability' mainly emerges when global equilibrium is achieved (Haugan, 2013). Sustainable program management focuses on providing essential information on the above-mentioned three major driving forces in the upcoming years, especially when designing programs. Hence, portfolio managers and senior planners all around the world are focusing on attaining a sustainable future (Haugan, 2013).

The article, "A conceptual framework of sustainability in project management oriented to success" was conducted by Mauro Luiz Martens and Marly Monteiro de Carvalho (2013) thereby using a systematic literature review. This article provides a conceptual framework, which helps in contributing to sustainable success in the fields of economic, environmental, and social perspectives in project management (Gimenez et al., 2012). Thus, sustainability is based on the triple bottom line concept (Savitz, 2006). Under this perspective, organizations, which are engaged in achieving a standard of excellence, must be developed for reducing their negative social along with environmental impacts.

Additionally, Carvalho and Rabechini (2011) claimed that there is a need for combining the environmental, social, and economic dimensions of sustainability into project management. This has further encouraged a discussion regarding the ways to upsurge sustainability in project management. According to Silvius et al. (2013), the relationship between project management and sustainable development is being considered by professionals along with scholars. According to Martens et al. (2013), initiatives have been already undertaken for integrating sustainable development and project management (Vifell \& Soneryd, 2012). However, additional researches are required to develop tools, techniques, and methodologies (Thomson et al., 2011). This can be applied in program management to analyze sustainability (Carvalho \& Rabechini, 2011).

Bebbington et al. (2007) further stated the significance of including variables of sustainability in activities associated with project phases to improve the quality of the projects. According to Shenhar (2011), the new perception of project management contributes to attaining success. In this scenario, the demand for sustainability in project management along with the concepts of success in projects has become relevant to the study (Shenhar \& Dvir, 2007). Wit (1988) asserted that success refers to the objectives along with the benefits of the project to the organization. It is the effectiveness of an initiative associated with the compliance of its initial objective, thereby enabling stakeholders to reap the benefits provided by the project. Herein, the need for studies on the convergence of sustainability issues and project management, when combined with the increasing importance of the current business environment and its relationship with success in projects can motivate the study. This mainly focuses on the development of the sustainability issues in project management and success in projects (Martens \& Carvalho, 2013).

Thus, this research paper focuses on aligning the above-mentioned themes to systematize a theoretical framework, which can provide evidence for constructing sustainability in program management to achieve success in programs.

\subsection{Definition}

In this research paper, the author's definition of a program is as follows: Different thematic and complementary sub-sets or projects (micro) designed to effectively contribute in tandem to a common set (macro). In this context, 
program sustainability can be defined as the act of reducing dependence on just a single source of funding along with shifting financial support for implementing the program. If there is only one project under implementation, it can be considered to be a program. The Program Life Cycle (PLC) as represented in Figure 1 below has been provided by Lainjo (2013).

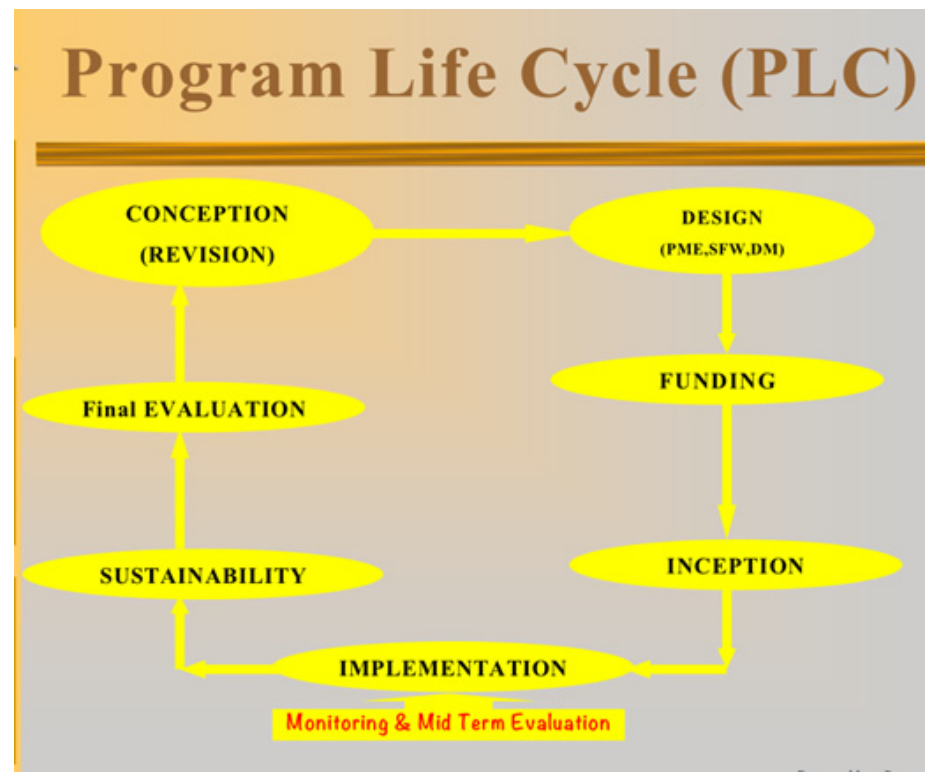

Figure 1. Program Life Cycle

Source: (Lainjo, 2013)

\subsubsection{Dynamics of Foreign Development Assistance Vis-a-Vis an Enabling Environment}

Morfaw (2011, p. 1) stated in this regard that "It is a proven truism that most projects are failing because of the lack of an appropriate sustainability plan". There is another way of putting the general perception of foreign aid in developing countries, which is, to perceive the glass to be half empty. Contextually, developing countries face complexities and diverse challenges while implementing project management programs. Hence, there is a tendency of solving some of the developmental challenges by addressing the symptoms. Thus, many of the issues raised in the set of questions listed above are completely ignored, sidelined, or carried forward to eradicate them. On the other hand, they also ignore some events that can take place and change the context for the better. For example, developmental assistance in the 20th century includes budget subsidies to national governments. This encompasses mechanisms such as structural adjustment programs. Hence, there were limited aspects to show effort even though many funding agencies have changed their policies in light of the foregoing statement concerning a proven truism (Boch-Isaacson \& USAID/Nepal, 2001). Debt forgiveness has become a key strategy in the last decade or so (National Bureau of Economic Research, 2016). Herein, debt forgiveness implies that the donor(s) failed to assess the local environment properly and perceive issues that may impede the implementation process (IMF, 2007). This further includes failure to design appropriate interventions and control the input-output ratio. Additionally, it cannot precipitate the desired outcomes. It also implies that recipients failed on their part to produce the expected results for a broad range of reasons. However, in any case, it is a "lose-lose" outcome.

\subsection{The Paris Agreement}

The "lose-lose" outcomes have resulted in the establishment of new "paradigms" of development partnerships. These include the Paris Agreement along with follow-up known as the Agra Agenda for Action, as well as the Busan Fourth High-Level Forum on Aid Effectiveness Conference of 2011. Additionally, there are other recent efforts, which seek to implement program interventions through international Non-Governmental Organizations (NGOs). The major objective of this activity is to improve accountability, reduce corruption, and foster better transparency (Funds for NGOs, 2008). On the other hand, the United Nations and its development programs are expected to monitor human development achievements of all countries, wherein it is represented. However, it is unclear, who monitors the success or failure of the implemented development programs at a global level (UNDP, 2015). 
The Paris Declaration, which was originally known as "The Aid Effectiveness Pyramid" (2005) was supported by more than 100 donors and developing countries (OECD, 2006). The Paris Declaration has strengthened the aid effectiveness by examining the behavioral changes along with identifying effective practices for partners along with donors at the time of implementing the Paris commitments (OECD, 2006). The donors and recipients at Paris agreed to adopt the strategic framework known as Management for Development Results (MfDR), which comprised broad strategic planning and risk assessment/management exercises, stated progress monitoring objectives, as well as outcome evaluation mechanisms (Ministry of Foreign Affairs of Denmark, 2008).

\section{What happened to the Paris Declaration?}

Since 2005, three surveys have been undertaken to understand the process and results of the implementation of MfDR. The results depicted that only one out of twelve goals was achieved (OECD, 2011). The goal that was achieved focused on strengthening the capacity of donor countries to align their programs with the national development strategies of developing countries. This helped in supporting the capacity development of the same. However, one of the negative outcomes was that the result may be disappointing in terms of overall expectations. Thus, it is important to see its achievement for shaping the "enabling environment", which is critical to subsequent success (Ministry of Foreign Affairs of Denmark, 2008).

\subsection{Total Quality Management (TQM)}

The concept of TQM requires a total commitment by everyone in an organization for making continuous improvements in all its practices, products, and services it provides to its customers. TQM can be referred to as an integrated management philosophy, which can be implemented in public, as well as private organizations. Furthermore, TQM focuses on meeting customers' expectations concerning quality to enhance customer satisfaction along with organizational performance (Scholar \& Rasheed, 2016).

What do managers and administrators of development in (LMICs) know about implementing ISO 9000 as the international standard for quality management? Shouldn't an investment be made in the early phase of program/project planning for key individuals to receive exposure to ISO?

Concerning the new development model, the involvement of project operatives in the development effort emphasizes that training in management systems is essential for enhancing capacity and accountability levels. The intended beneficiaries are to be involved herein whenever possible. This is highly expected if the joint effort is following the Paris Declaration model and MfDR core principles. This can help in meeting the criteria of Maslow's third level (refer to figure 2 below).

\subsection{Strengthening Public Institutions}

\subsubsection{Democracy First, Development Second}

The prevailing myth, as developed by some experts seems to depict the absence of a democratic setting. This is one of the key problems that affect success. However, this can be perceived as a misguided assertion. In the context of democracy, the political views about the same have been defined by the western society, which was implemented as a solution to Africa's (and other developing countries') perpetual problem (Busia, 1961). As a result, mindsets were highly influenced by such persuasive and naive pronouncements, which stated that any attempt to observe things differently has limited the attainment of success. Additionally, a more egregious tendency is attempting to characterize an entire country, a continent, or way of life, as a failure. Such dismissive and disingenuous falsehoods can be considered to be misleading.

\subsubsection{The Changing Development Paradigm}

In the context of pessimism concerning the achievement of developmental outcomes, many funding agencies have continuously changed their policies and procedures. These changes focused on re-establishing development paradigms such as the Paris Declaration on AID Effectiveness of 2005. In recent times, the agencies have also been trying to channel program interventions through contracts with larger not-for-profit development entities such as WINROCK, John Snow, Inc., BRAC, and CHEMONICS among others. The organizations are supposedly changing the aid landscape for the better. It has become the new norm for supporting recipients to forge their national development strategies with their parliaments and electorates (ownership). It has also been helpful for donors to support these strategies (alignment) and work to streamline their efforts in-country (harmonization). Furthermore, this strategy has assisted in developing policies to achieve goals and monitor the same. Herein, donors and recipients are jointly responsible for achieving these goals (mutual accountability). Several years after the Paris Declaration and despite the summation of development principles reflected in the Accra Agenda for Action, a review was conducted by considering a renewed approach. However, the results were not satisfactory. In 2011, the Busan Partnership for Effective Development Co-operation recognized that there is a need for 
successfully addressing poverty and inequality. This will help in developing a better world. Thus, joint efforts are required for addressing a wide range of challenges by leveraging and strengthening the impact of diverse sources of funds along with knowledge (Organization for Economic Co-operation and Development, 2011). In effect, it depicted that prior efforts such as the Sector Wide Approach were used for development. This focused on operating principles and practices within a narrow sector basis rather than policies \& activities, politics, and institutional issues affecting the public more broadly, did not address the complexities of development assistance completely (Foster, 2000).

The international development community continues to search for a more appropriate model. This is mainly to explicitly capture the complexities and produce more sustainable along with valuable outcomes.

\subsection{Sustainability and Enabling Environment}

The discussion started by defining the elements of a 'gold standard', which was developed based on the BottomUp Strategy (BUS) foundation or philosophical and moral platform (IISD, 2019). Thus, with a comprehensive strategic planning process, the intended beneficiaries convey their specific needs to the respective government representatives and development partners. Some of the elements of this process include stipulations of food scarcity, which must be eliminated. Additionally, access to safe household drinking water along with reducing mother and infant mortality needs to be maintained. There is a need for putting better efforts to provide primary/secondary education for boys and girls, whose completion ratio must be improved. Besides, the agricultural output and employment rates must be increased and diversified simultaneously. Furthermore, the numbers/percentages/proportions of people living in/at/below the poverty level must be alleviated. Additionally, HIV and AIDS must be prevented, while the patients are to be treated with care.

The accomplishment of these laudable goals is sometimes perceived to be easier. Hence, the country-specific development plans are often formulated under the guidance of the United Nations Development Program (UNDP), wherein funding is usually available in the form of multilateral assistance. This includes major development banks and the International Monetary Fund (IMF). Additionally, bilateral development assistance programs are formulated with the richest/developed countries in parallel to those of the UN. This is because individual donors and lenders have their foreign policy objectives (United Nations, 2007).

Neither of the above-mentioned approaches necessarily addresses the problems of making development processes sustainable. Additionally, the intended beneficiaries appear to not have been comprehensively consulted in the strategic planning process nor were they a vital part of the monitoring and feedback processes during implementation phases. The intended beneficiaries were actively involved in post-implementation evaluation and stock-taking.

\subsection{Principles of Sustainable Development}

The six principles of sustainable development include 'conversation of ecosystem', 'development of sustainable society', 'conversation of biodiversity', 'control of population growth', 'conversation of human resource', and 'increasing participation of people' (Kullabs, n.d.). The conversation of ecosystem focuses on conserving ecological systems and preserving the aquatic and terrestrial ecosystems. Herein, it must be mentioned that the development of a sustainable society significantly depends on a balanced diet, healthy residents, health services, quality education, and employment among others. This helps in developing a positive attitude to the natural environment. The conversation of biodiversity focuses on conserving natural resources and is an essential aspect to protect human beings. Control of population growth is also important for the efficient use of available resources, which is vital for maintaining sustainability in the long run. Besides, the conversation of human resources is found to be imperative, as people play an essential role in conserving the environment. Therefore, increasing the participation of people can help in attaining sustainability collaboratively (Kullabs, n.d.). 


\subsection{The CARROT-BUS and Maslow's Model}

What would be a viable BUS? How would an adult constituency, and associated institutions in charge of maintaining that constituency, be convinced that the intervention was a beneficial intervention? Who will take ownership if desired results are either not known or doubtful in each stage of the development?

Concerning the above-stated question, an individual must have a proper understanding of the issue of human behavior such as Abraham Maslow's hierarchy of needs model presented in below figure 2 (Education Library, 2021). Additionally, it is unlikely that most of the intended beneficiaries would have achieved the top-most level of Maslow's pyramid i.e. self-actualization. However, there is a presupposition that the beneficiaries had attained level 1 , thereby depicting basic safety needs. This includes assuring basic security and protection. However, the majority of the intended beneficiaries would not visualize the larger picture. This includes the level of selfactualization of a positive or negative outcome later on in a lifetime (Education Library, 2021).

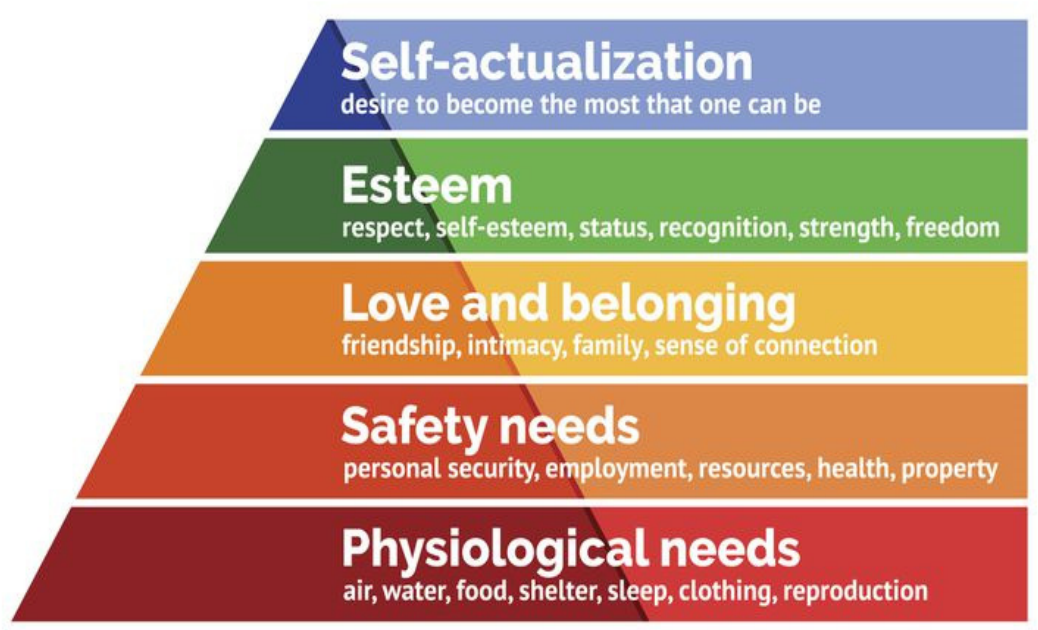

Figure 2. Abraham Maslow’s hierarchy of needs

Source: (Education Library, 2021)

The intended beneficiaries need to be convinced that the use of the proposed resource(s) is in the interest of achieving one or more hierarchy of needs. Foreign aid for peaceful development purposes is supposed to add resources to the existing budgets to expedite the attainment of results (Education Library, 2021). This is mainly with the motive that the intended beneficiaries will start taking ownership once they perceive a positive outcome of the development intervention. Nevertheless, the beneficiaries are less concerned whether the source of such aid is provided by the state or through foreign assistance. In the Maslow model, the primary assumption is that the recipients' first aim is to satisfy their needs for the resources and the knowledge/know-how necessary to obtain the lowest level and then move to higher levels (Education Library, 2021). The bottom level of Maslow's hierarchy model depicts the basic human needs such as food and water, clothing, shelter, and physical security. In other words, physiological needs are important for life and health. These are vital antecedents for a person to attain next level needs (Education Library, 2021).

What if one treats the development process like a person striving to satisfy one need after another in the Maslow model?

The above-mentioned question implies that the recipient country strives to develop its capacity to become more responsible and accountable, especially when recipients are individual citizens of the state, who are incorporated in the development process and not merely bystanders. The attainment of self-actualization implies that ownership has incurred the desired outcome. If they are neither a citizen nor incorporated, the difficulties of building sustainability multiply (Yawson, Armah, \& Pappoe, 2009).

Nonetheless, it is difficult to demand transparency from a recipient government, especially when specific ownership is elusive. Correspondingly, ownership seems to communicate to the next highest level of Abraham Maslow's hierarchy such as (self)-esteem and recognition. This would presuppose that there have been the attainment of social needs and a sense of belonging (Education Library, 2021). If the full range of needs of 
beneficiaries has been achieved, then the "T", or trust principles in TQM, and the "R", implicit in the risk management analysis component of MfDR would have been successfully managed.

Conversely, who will take ownership if the desired results are either unclear, unknown or doubtful among the intended beneficiaries? Or if the use of resources allocated is not accounted for or remains unknown? Or if the bigger picture, the outcome, is either unknown or misunderstood?

To be successful, the key elements of a gold standard development model include capacity along with accountability, resources, results, ownership, and transparency. These aspects are the key component of the CARROT bus model. In the Maslow model, these elements are perceived as a natural progression, which leads to self-actualization.

In any viable model, the framework can be referred to as an enabling environment, which is defined as the availability of appropriate, relevant, and sustainable laws, policies, and political stability. It is further defined by the advocacy of effective coordination mechanisms and strategies to enable the successful realization of planned objectives/outcomes alongside contributing to an overall higher goal.

\subsection{The CARROT-BUS Model}

Since it has already been mentioned in this article, reference was made to the processes of establishing an appropriate enabling environment. Additionally, an appeal was made for the emergence of one or more structured gold standard program management models. The central strategy was to develop the management model based on the BUS model, which is interrelated to several elements of Maslow's hierarchy model. This includes capacity building, personal, and institutional accountability, effective utilization of resources, acknowledgment of both desired \& undesired results, group \& community ownership, and transparency of the process (CARROT).

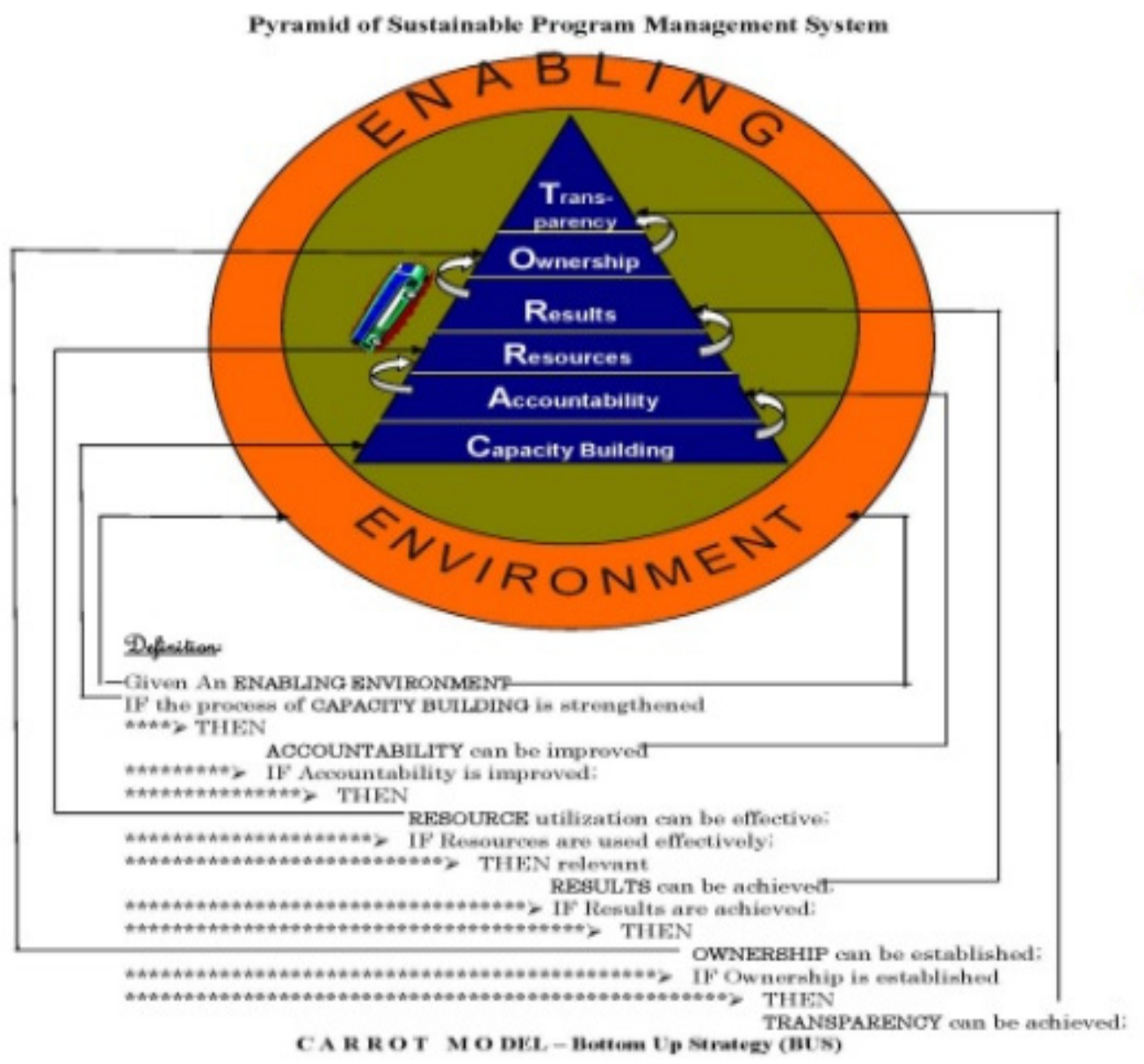

Figure 3. Pyramid of sustainable program management (CARROT-BUS Model) 


\subsubsection{Capacity Development}

The capacity building occupies the bottom level of the CARROT-BUS model. Capacity building refers to the development of both individuals and a group of citizens as a whole to perform sustainable tasks. This enables them to grow and improve in educational, knowhow \& economic terms, and in their willingness to exercise social responsibilities beyond those dictated by family-kinship mores, religious precepts, and social norms of their ethnicity. In this model, the key components of capacity building include workshops, training programs, skills updates, operations research, community mobilization, appropriate campaign activities, and creating community awareness. It is considered to be important because it is highly associated with the experience, wherein aid-funded programs could not deliver results on time due to lack of government capacity.

\subsubsection{Accountability}

The concept of accountability is to ensure that individuals, communities, NGOs, governments, and donors are aware of the objectives or goals to accomplish. A senior international executive, Toben Rick used the SIMPLE approach to emphasize the meaning of the word accountable (Rick 2011). "S" stands for the setting of expectations. Herein, if people are not made aware of the objectives, they should not be blamed for failure. Besides, "I" refers to as invite commitment, as without commitment, people can always give excuses to complete their tasks. "M" stands for a way to measure progress. If there is no quantitative way of measuring the accountability of the stakeholders, an individual, the community, an NGO partner, or even a government can always qualify performance from another self-defined perspective. This helps in claiming the required accountability for the achievement of an un-quantified result or objective. "P" infers provision of feedback, which allows ways to perform better and precisely quantify accountability for performance. "L" stands for the link to rewards and punishments. In this regard, a sound management plan needs to precisely-define consequences for producing both the right as well as the wrong result(s). "E" means the evaluation of results. Herein, the accountability record of all individuals, communities, and the official managers of development funds must be objectively checked to determine whether the intended results have met the expectations as articulated by the partners and stakeholders (Rick 2011).

\subsubsection{Resources}

Resources normally comprise written plans, funds, materials, equipment, technologies, training needed, and/or expertise necessary to produce the desired results. The timely delivery of essential resources is also part of this conundrum. Thus, designing and maintaining a sufficiently flexible administrative system(s) through which the aforementioned physical and technical resources are most effectively delivered is a major challenge. A significant gap exists between the provision of essential resources and accountability for their value when delivered. According to a report published by the United Nations Development Program (UNDP), \$1 trillion illegal payments (bribes) are paid from development funds annually (UNDP, 2016). Corruption has been identified as a major barrier to sustainable development along with undermined democracy (UNDP, 2012). Thus, accountability needs to be ensured to optimize the effective use of resources allocated to the program.

\subsubsection{Results}

The first three elements, including capacity, accountability, and resources are often combined and labeled as "inputs". On the other hand, outcomes include ownership of the development process (sustainability effect) and transparency throughout the development process. Result also contains an element of ambiguity and can be defined as a specific output, a more general outcome or purpose, or as the achievement of a broader goal (USAID-Ethiopia, 2015). The first law of results is that each one has to be quantifiable for measurement. These can either be intended, unintended, positive, or negative. The creation of ownership and the achievement of transparency, as well as results in some sense, are more difficult to define in immediate and measurable terms.

\subsubsection{Ownership}

Ownership is often fraught with ambiguity. An OECD publication states that the Paris Declaration referred to ownership as the developing countries' governments' abilities to execute leadership concerning their development policies along with strategies and coordinate development actions (OECD, 2011). Since then the international dialogue has recognized the need for broader definitions of ownership. The Accra Agenda for Action (2008) expanded the concept of ownership from merely the executive branch of whatever host government the donor was dealing with "to the broader society of that country as owners of development efforts" (OECD, 2011). Ideally, ownership of the development process should be from start to finish irrespective of positive or negative outcome/failure. Attaining ownership at the offset would imply that all stakeholders had agreed on the indicators or measurements. 


\subsubsection{Transparency}

Transparency in foreign aid assistance can be defined as the "comprehensive availability and accessibility of aid flow information in a timely, systematic, and comparable manner that allows public participation in government accountability" (Moon \& Williamson, 2010). Ideally, transparency assumes that everybody involved in a development program is capable of being qualified to adhere to the management and fiscal accounting system(s). It also emphasizes executing approved plans. If transparency is the outcome of ownership, whoever owns the project should be open about the facts regarding the use of development funds in the project implementation plan as a road map. However, it is also true that transparency can be viewed differently.

The funders/donors prefer the recipients/beneficiaries to be transparent about government spending. Transparency also demands the "full disclosure of all relevant government fiscal information" on a timely basis (Moon \& Williamson, 2010). Hence, it is to be done in such a way that the public can check the accountability of the government (Moon \& Williamson, 2010). The Paris Declaration development paradigm communicates the degree of transparency desired, which can be achieved. However, this is only possible if there are capable and authorized people to take ownership of foreign aid, often as proxies of the host government.

Accusations of malfeasance in management are made, which portrays corruption in government or the party vested with project oversight and management. This is done without identifying the individuals to take ownership over certain processes such as communication of factual data about the budget and the actual amounts of foreign aid received. If executing and disbursing authorities are properly trained, as well as authorized, they may be held responsible for the deployment of resources. These specific authorities need to ensure the availability of information regarding the implementation process in terms of the flow of resources to the final beneficiaries. These authorities are to be provided with some sort of "bulletproofing", as political interference is generally a norm in most developing countries when foreign aid is involved. Donors need to feel more comfortable with joint ownership of results along with joint transparency rather than being threatened by reports of corruption \& failures by various oversight entities.

Additionally, the opposite of transparency is corruption. In this context, corruption affects the goal of transparency and destroys the entire development model such as Maslow's, MfDR, CARROT-BUS, or any other. Therefore, any development effort that purports itself to be valid and sustainable must have had a component to address corruption.

\subsection{CARROT-BUS Model Justification}

Perceptive readers will notice a close similarity between the CARROT model and Maslow's hierarchy of needs (refer to above figure 2), which is also illustrated in the form of a pyramid. The CARROT model includes bodily needs at the bottom of the pyramid and spiritual needs at the top. On the other hand, the Maslow model ranges from basic to social science that all readers must be familiar with. However, it is familiar because it is useful along with describing the ways to conduct development work. Similar to Maslow's hierarchy of needs, the CARROTBUS is essentially a model comprising a human dimension. It is important to remember that the top of the pyramid owes a debt to those at the bottom. This is because the attainment of the bottom pyramid helps in, realizing selfactualization, which is the highest degree of satisfaction. It would be wrong for donors to address their own needs such as belongingness and esteem by development projects. Herein, the key focus must be on the clients. It is essential to ensure that all basic needs are met throughout the world so that all of humanity can make it to the top layer of the pyramid i.e. self-actualization. Anything less perpetuates a state of injustice.

Additionally, it is to be remembered that donors have needs as well. One of the self-actualization needs in the pyramid includes "generativity," or the ability to pass on wisdom, know-how, and even material possessions to the next generation. Based on a different perspective, it has been understood that the western countries, which have scaled the "development" pyramid, cannot continue to focus on the need for "safety" exclusively. Furthermore, it should not focus on over-satisfying their physiological needs when others are starving. At the same time, the drive for development must come from below, and thus "bottom-up strategy" can be followed herein. Donors must acknowledge and honor the urgency of their clients to forge relationships mutual respect, and trust; for accomplishing the set goals. Thus, capacity, accountability, resources, results, ownership, and transparency can be considered to be highly critical.

\section{Research Methodology}

The study has integrated a qualitative study with the support of secondary data for understanding the selected issue in detail (Bruce et al., 2017). The integration of a qualitative research approach has been conducted, as it has helped in gathering, as well as interpreting the data. In this context, secondary data has been collected from secondary sources, including scholarly journals, books, and other reliable websites. Additionally, the study also has conducted 
a literature review for understanding the importance of sustainable development in project management. Hence, the integration of a qualitative approach along with secondary data has significantly helped in understanding the identified issue in detail. Furthermore, one of the major advantages of using secondary data is that they are already available, as it is provided by researchers who are experts in their respective fields. Besides, secondary data are used because it is considered to be a reliable source of information (University College London, 2020).

\section{Discussion}

There are substantial numbers of evidence-based reports, which support high levels of social inequality along with the unacceptable quality of life imbalance in LMICs. Geopolitically, there are a significant number of compelling evidence-based and anecdotal reports with similar instances of dismal social inequality in many indigenous, as well as vulnerable populations in some rich Western countries such as Australia, Canada, and the United States. Efforts made by these governments to improve the quality of life in these vulnerable and indigenous communities have been a colossal fiasco. Based on this documented evidence, the CARROT-BUS model is "universally" applicable to LMICs. Hence, a compelling analytical review of global thematic social indicator dynamics, including life expectancy, infant mortality rates, risk of chronic diseases, and school completion rates confirm the appropriateness of this framework in Indigenous and other vulnerable populations. This further includes suicide rates, alcoholism, and access to meaningful jobs, household income, incarceration rates, child abuse, along domestic violence.

The results of foreign aid and international development are being continuously combined. There is compelling anecdotal and scientific evidence that foreign aid outcomes have ranged from dismal to reasonable. Many beneficiaries continue to live in squalid conditions. Besides, poverty remains ubiquitous despite reports to the contrary and improved quality of life among vulnerable populations remains a problem. Additionally, the rich western countries have failed to meet their pledges to donate $0.7 \%$ of their GDP to LMICs. Only seven countries have achieved this objective (OECD, 2016). Therefore, the Paris Declaration, which was promulgated to address most developmental concerns, has been disappointing to a large extent.

In cases where attempts to bridge these social gaps are being made, are the respective funding institutions getting their money's worth? Are effective and meaningful results being achieved?

As per the report findings of the Canadian Auditor General (AG), the research paper indicated that over eight years (i.e. from 2010 to 2018), the Canadian government had spent a total of C $\$ 2.4$ billion on-job-training or capacity building. This was mainly for the lowest level of the CARROT-BUS pyramid, comprising the Indigenous peoples in Canada. An additional C $\$ 300$ million was spent on the government's "Skills and Partnership Fund" annually. In its review, the AG characterized the program's outcome as an "incomprehensible failure". The evaluation report further highlighted the unawareness of the government in the program's success. This is done to help Indigenous people find sustainable employment. Hence, this is one of the copious examples to deliver meaningful results (Government of Canada, n.d.).

Readers, who have followed reports on our indigenous communities and their respective developmental challenges, will easily resonate with the research paper and other documented cases. Statistics confirm the abominable and unacceptable levels of access and the use of social services in most of these communities. Disjointed and lackluster efforts by the funding governments including the absence of effective participation by these vulnerable groups are part of the problem. LMICs suffer the same dilemma. Thus, the efforts including financial commitments by national governments continue to raise red flags, disapproval, and polarization. Additionally, bureaucrats at the national and international levels need a significant paradigm shift. It has also been found that current bureaucratic processes are complex, convoluted, generally exclusive, and unproductive. Hence, an enhanced and more accountable approach needs to be their operating mantra. Tax dollars deserve more than what is being achieved. Thus, a more effective, inclusive, and participatory oversight is an invaluable component of an effective, and viable, along with sustainable program management strategy.

\section{Conclusion}

Based on the overall findings, sustainable project management can be inferred as a plan for monitoring along with controlling the overall project delivery process. It needs to consider the economic, environmental, and social aspects concerning the life-cycle of the resources in a project. These resources, deliverables, processes, as well as effects, helped in providing benefits to the stakeholders, as the entire process is performed fairly and transparently. However, attaining sustainability requires people to engage in the project along with the programs actively.

\subsection{Limitation and Future Scope}

The study mainly focused on understanding the importance of sustainable development by considering the topic 
of project management. The limitation of the study has been that there have been limited sources concerning the issue. Furthermore, the model, which has been selected in this study i.e. the Carrot-Bus model, lacks literary sources. Hence, this model cannot be explained or described adequately, which has affected the quality of the overall study. Additionally, the study lacked a sufficient relationship between the Carrot-Bus model and Maslow's hierarchy model. Thus, it can be recommended that future researchers can focus on conducting studies by considering topics or issues that are easy to find. Future researchers by focusing on the above-mentioned aspects can conduct valid research. However, with the collection of valuable information, this study can also act as a source of information for future researchers.

\section{References}

Asian Development Bank. (2020). Guidelines for preparing and using a design and monitoring framework. Sovereign Operations and Technical Assistance, 1-60. Retrieved from https://www.adb.org/sites/default/files/institutional-document/32509/guidelines-preparing-dmf.pdf

BCI. (2019). GIZ- BCI project coordinator. Implementation Coordinator, 1-6. Retrieved from https://bettercotton.org/wp-content/uploads/2019/08/GIZ-BCI-Project-Coordinator_JD.pdf

Bebbington, J., Brown, J., \& Frame, B. (2007). Accounting technologies and sustainability assessment models. Ecological Economics, 61, 224-236. Retrieved from https://www.academia.edu/28803730/Accounting_technologies_and_sustainability_assessment_models

Biscaye, P. E., Reynolds, T. W., \& Anderson, C. L. (2017). Relative effectiveness of bilateral and multilateral aid on development outcomes. Review of Development Economics, 21(4), 1425-1447. Retrieved from https://onlinelibrary.wiley.com/doi/pdf/10.1111/rode.12303

Boch-Isaacson, J. M. (2001). Half-a-century of development: The history of US assistance to Nepal, 1951-2001. United States Agency for International Development.

Briassoulis, H. (2001). Sustainable development and its indicators: Through a (Planner's) glass darkly. Journal of Environmental Planning and Management, 44(3), 409-427. Retrieved from https://www.tandfonline.com/doi/abs/10.1080/09640560120046142

Bruce, N., Pope, S., \& Stanistreet, D. (2017). Quantitative methods for health research. Wiley and Sons. Retrieved from

https://books.google.co.in/books?id=jghCDwAAQBAJ\&pg=PT755\&dq=Bruce,+N.+et.al.,+2017.+Quantita tive + Methods + for + Health + Research\&hl $=$ en \&newbks $=1 \&$ newbks_redir $=0 \& s a=X \& v e d=2 a h U K E w j Z 4 K G T$ 8I7uAhWKV30KHeqcBS4Q6AEwAHoECAYQAg\#v=onepage\&q=Bruce\%2C\%20N.\%20et.al.\%2C\%2020 17.\%20Quantitative\%20Methods\%20for\%20Health\%20Research\&f=false

Busia, K. A. (1961). The prospects for democracy in Africa. Retrieved 2021, from https://home.koranteng.com/writings/prospects-democracy-africa-lecture.html

Carvalho, M. M., \& Rabechini, R. (2011). FundamentosemGestão de Projetos: Construindocompetênciasparagerenciarprojetos: Teoria e casos. $3^{a}$ ed. São Paulo: Atlas, 422p. Retrieved from https://www.researchgate.net/publication/299284044_Fundamentos_em_Gestao_de_Projetos_Construindo_ Competencias_para_Gerenciar_Projetos/link/56f047d308ae584badc9309a/download

Chawla, V., Chanda, A., Angra, S., \& Chawla, G. (2018). The sustainable project management: A review and future possibilities. Journal of Project Management, 3(3), 157-170. Retrieved from $\mathrm{http}: / / \mathrm{m}$.growingscience.com/jpm/Vol3/jpm_2018_6.pdf

De Wit, A. (1988). Measurement of project success. International Journal of Project Management, 6(3), 164-170. Retrieved from https://www.sciencedirect.com/science/article/abs/pii/0263786388900439

Dvir. D., Raz, T., \& Shenhar, A. (2003). An empirical analysis of the relationship between project planning and project success. International Journal of Project Management, 21, 89-95. Retrieved from https://www.sciencedirect.com/science/article/abs/pii/S0263786302000121

Education Library. (2021). Maslow's hierarchy of needs in education. Retrieved 2021, from https://educationlibrary.org/maslows-hierarchy-of-needs-in-education/

Foster, M. (2000). New approaches to development cooperation: What can we learn from experience with implementing sector wide approaches? Centre for Aid and Public Expenditure, 6-43. Retrieved from https://www.odi.org/sites/odi.org.uk/files/odi-assets/publications-opinion-files/2075.pdf

Funds for NGOs. (2008). Swiss Agency for Development and Cooperation, The (SDC). Retrieved 2021, from 
https://www.fundsforngos.org/bilateral-funds-for-ngos/the-swiss-agency-funding-support-to-ngos/

Gimenez, C., Sierra, V., \& Rodon, J. (2012). Sustainable operations: Their impact on the triple bottom line. International Journal of Production Economics, 140(1), 149-159. Retrieved from https://www.sciencedirect.com/science/article/abs/pii/S0925527312000503

Government of Canada. (n.d.). Partnership to fund gender equality and the empowerment of women and girls in Canada and abroad. Retrieved 2021, from https://www.international.gc.ca/gac-amc/campaigncampagne/gender_equality-egalite_des_genres/index.aspx?lang=eng

Haugan, G. (2013). Sustainable program management. CRC Press. Retrieved from https://books.google.co.in/books?id=Fad7AAAAQBAJ\&printsec=frontcover\&source=gbs_ge_summary_r $\& \mathrm{cad}=0 \# \mathrm{v}=$ onepage $\& \mathrm{q} \& \mathrm{f}=$ false

IISD. (2019). Gold standard, partners issue guidance for activity-level Sdg impact reporting. Retrieved 2021, from https://sdg.iisd.org/news/gold-standard-partners-issue-guidance-for-activity-level-sdg-impact-reporting/

IMF. (2007). Debt reorganization and related transactions. Debt Reorganization, 245-254. Retrieved from https://www.imf.org/external/pubs/ft/bop/2007/pdf/appx2.pdf

Kullabs. (n.d.). Principles of sustainable development. Retrieved 2021, from https://kullabs.com/class-8/science8/environment-and-sustainable-development/principles-of-sustainable-

development\#: :text=List\%20out\%20any\%20six\%20principles\%20of\%20sustainable\%20development.\&te $\mathrm{xt}=$ Development $\% 20 \mathrm{of} \% 20$ sustainable $\% 20$ society,Control\%20of\%20population $\% 20$ growth

Lainjo, B. (2013). Monitoring and evaluation. Data Management Systems, p. 4.

Martens, M. L., Brones, F., \& de Carvalho, M. M. (2013). Lacunas e tendências na literatura de sustentabilidade no gerenciamento de projetos: uma revisão sistemática mesclando bibliometria e análise de conteúdo. Gestão e Projetos: GeP, 4(1), 165-195. Retrieved from https://dialnet.unirioja.es/servlet/articulo?codigo=5078073

Ministry of Foreign Affairs of Denmark. (2008). Thematic study on the Paris declaration, aid effectiveness and $\begin{array}{lllll}\text { development } & \text { effectiveness. } & \text { OECD, } & \text { Retrieved } & \text { from }\end{array}$ http://www.oecd.org/development/evaluation/dcdndep/41807824.pdf

Moon, S., \& Williamson, T. (2010). Greater aid transparency; crucial for aid effectiveness. Retrieved 2021, from http://www.odi.org.uk/resources/docs/5722.pdf

Morfaw, J. N. (2011). Project sustainability: A comprehensive guide to sustaining projects, systems and organizations in a competitive marketplace. iUniverse. Retrieved from https://books.google.co.in/books?hl=en\&lr=\&id=0 wJdNRxpDcAC\&oi=fnd\&pg=PR1\&dq=John+N.+\%26+ Morfaw, + J. $+(2011) .+$ Project + Sustainability: + A + Comprehensive + Guide + to + Sustaining\&ots $=$ XToxmxd8S5 $\&$ sig $=-$

zfgSHc_EEvQolF3QU60LOvDZkg\&redir_esc=y\#v=onepage\&q=John\%20N.\%20\%26\%20Morfaw $\% 2 \mathrm{C} \%$ 20J.\%20(2011).\%20Project\%20Sustainability\%3A\%20A\%20Comprehensive\%20Guide\%20to\%20Sustaini $\mathrm{ng} \& \mathrm{f}=$ false

National Bureau of Economic Research. (2016). Corrupt Governments receive no less November foreign aid. Retrieved 2021, from http://www.nber.org/digest/nov99/w7108.html

OECD. (2006). Aid effectiveness: Three good reasons why the Paris Declaration will make a difference. Development Cooperation Report, 7(1), 49-54. Retrieved from www.oecd.org/development/effectiveness/36364587.pdf

OECD. (2011). The Busan partnership for effective development co-operation. Retrieved 2021, from http://www.vitainternational.media/en/article/2016/04/13/development-aid-rises-again-in-2015-spendingon-refugees-doubles/326/

OECD. (2016). Development aid rises again in 2015, spending on refugees doubles. Retrieved 2021, from http://www.vitainternational.media/en/article/2016/04/13/development-aid-rises-again-in-2015-spendingon-refugees-doubles/326/

Organization for Economic Co-operation and Development. (2011). The Paris Declaration. Retrieved November 30, 2016, from http://www.oecd.org/development/aideffectiveness/48742718.pdf

Rick, T. (2011). How to hold people accountable- Performance Management. Retrieved 2021, from http://www.torbenrick.eu/blog/performance-management/how-to-hold-people-accountable/ 
Savitz, A. W. (2006). The triple bottom line: how today's best-run companies are achieving economic, social and environmental success - and how you can tool. John Willey \& Sons. Retrieved from https://www.amazon.in/Triple-Bottom-Line-Companies-Environmental/dp/0787979074

Scholar, M., \& Rasheed, F. (2016). Impact of Total quality management on customer satisfaction. International Journal of Management and Commerce Innovations, 4(2), 702-709. Retrieved from https://www.researchgate.net/publication/331558637_Impact_of_Total_Quality_Management_on_Custome r_Satisfaction

Shenhar, A. (2011). Meeting time, cost, and moneymaking goals with strategic project leadership. Retrieved 2021, from https://www.pmi.org/learning/library/meeting-goals-strategic-project-leadership-6112

Shenhar, A. J., Dvir, D., Levy, O., \& Maltz, A. C. (2001). Project success: a multidimensional strategic concept. Long range planning, 34(6), 699-725. Retrieved from https://www.sciencedirect.com/science/article/abs/pii/S0024630101000978

Shenhar, A., \& Dvir, D. (2007). Reinventing project management: The diamond approach to successful growth and innovation. Harvard Business School Press. Retrieved from https://books.google.co.in/books?hl=en\&lr=\&id=f5_BAgAAQBAJ\&oi=fnd\&pg=PR7\&dq=Shenhar,+A.,+ D. +Dvir.+2007.+Reinventing + project+management:+The+diamond+approach + to + successful +growth + and + innovation\&ots=b1i5yZ3bi7\&sig=OOmhMJ8D_5H9YbhPLtVG8Tqouk4\&redir_esc $=\mathrm{y} \# \mathrm{v}=$ onepage \&q=S henhar\%2C\%20A.\%2C\%20D.\%20Dvir.\%202007.\%20Reinventing\%20project\%20management\%3A\%20T he $\% 20$ diamond $\% 20$ approach $\% 20$ to $\% 20$ successful $\% 20$ growth $\% 20$ and $\% 20$ innovation $\& \mathrm{f}=$ false

Silvius, A. J. G. (2013). Sustainability in project management processes. IGI Global Publishing.

Singh, K. N. (2020). 2020: Anything that could go wrong went wrong. Retrieved 2021, from https://www.sundayguardianlive.com/opinion/2020-anything-go-wrong-went-wrong

Thomson, C. S., El-Haram, M. A., \& Emmanuel, R. (2011). Mapping sustainability assessment with the project life cycle. Proceedings of the ICE - Engineering Sustainability, 164(2), 143-157. Retrieved from https://www.icevirtuallibrary.com/doi/abs/10.1680/ensu.2011.164.2.143

UNDP. (2012). Helen Clark: Remarks on corruption at the ECOSOC 2012 high level segment. Retrieved 2021, from http://www.undp.org/content/undp/en/home/presscenter/speeches/2012/07/09/helen-clark-openingremarks-at-the-ecosoc-2012-high-level-segment/

UNDP. (2015). Implementing-the-Paris-Declaration-on-aid-effectiveness. Retrieved 2021, from https://www.undp.org/content/undp/en/home/librarypage/capacity-building/implementing-the-parisdeclaration-on-aid-effectiveness.html

UNDP. (2016). Anti-Corruption. $\quad$ Retrieved 2021, from http://www.undp.org/content/undp/en/home/ourwork/democraticgovernance/focus_areas/focus_anticorruption.html

United Nations. (2007). The United Nations development agenda: Development for all. Economic \& Social Affairs, 1-82. Retrieved from https://www.un.org/esa/devagenda/UNDA1.pdf

University College London. (2020). Secondary data analysis. Using Secondary Data, 1-2. Retrieved from https://ethics.grad.ucl.ac.uk/forms/Secondary-data-analysis-file-note.pdf

USAID-Ethiopia. (2015). Country development cooperation strategy 2011 - 2015. Accelerating the Transformation toward Prosperity, 2-72. Retrieved from https://rmportal.net/library/content/usaid-ethiopiacountry-development-cooperation-strategy-2011-2013-2015/view

Vifell, Å. C., \& Soneryd, L. (2012). Organizing matters: How 'the social dimension'gets lost in sustainability projects. Sustainable development, 20(1), 18-27. Retrieved from https://onlinelibrary.wiley.com/doi/abs/10.1002/sd.461

Yawson, D. O., Armah, F. A., \& Pappoe, A. N. (2009). Enabling sustainability: Hierarchical need-based framework for promoting sustainable data infrastructure in developing countries. Sustainability, 1(4), 946-959. Retrieved from

https://scholar.google.com/scholar?hl=en\&as_sdt=0\%2C5\&q=Enabling+Sustainability\%3A+Hierarchical + Need-

Based + Framework + for + Promoting + Sustainable + Data + Infrastructure + in + Developing + Countries $\& b t n G=$ 


\section{Copyrights}

Copyright for this article is retained by the author(s), with first publication rights granted to the journal.

This is an open-access article distributed under the terms and conditions of the Creative Commons Attribution license (http://creativecommons.org/licenses/by/4.0/). 